\title{
EL MUNDO EN UNA NUEZ: DE CALCUTA Y \\ CANTÓN A BUENOS AIRES EN UNA ÉPOCA DE GUERRA. LA INTRODUCCIÓN DE EFECTOS ASIÁTICOS EN LOS MERCADOS SURAMERICANOS, 1805-1807
}

\author{
ANTONIO IBARRA \\ Universidad Nacional Autónoma de México ${ }^{\mathrm{a}}$
}

The World in a Nutshell: from Calcutta and Canton to Buenos Aires during Wartime. The Introduction of Asian Goods in South American Markets, 1805-1807

\begin{abstract}
This article explores the impact of Asian goods in the Rio de la Plata area through the navigation course of two frigates of the Royal Company of Phillipines, forced by the maritime conflict between the Spanish and British Empires, dock in the Southern estuary. Examining the value and traits of the shipment and the details of the 'comercio de pacotilla', this study analyzes the distribution of the goods from China, Philippines and in particular, India, in the port basin, the hinterland of the Viceroyalty, and its connections to the Alto Peruvian space, the trans-Andean region, and the Littoral way to Paraguay. This episode enables an understanding of the distribution of goods, as well as a more detailed recognition of the actors of this traffic and a renewed evaluation of the role of the company in the global market of Asian goods.
\end{abstract}

Keywords: Global History, Asia and America Trade, Navigation and War, Rio de la Plata

JEL Classification: N15, N46, N76, N26

\footnotetext{
a Facultad de Economía. ibarrara@unam.mx http://antonioibarra.com.mx/
} 


\section{RESUMEN}

Se explora el impacto de las mercancías asiáticas en el Rio de la Plata a partir de la navegación de dos fragatas de la Real Compañía de Filipinas, que forzadas por el conflicto marítimo angloespañol recalan en el estuario rioplatense. A partir del examen de valores y características de la carga del "comercio de pacotilla", se analiza la distribución de los efectos de China, Filipinas y particularmente de la India, en la cuenca portuaria, el Interior del virreinato y sus conexiones con el espacio altoperuano, transandino y del Litoral. El episodio permite advertir la distribución de la oferta de mercancías, a los actores de este tráfico y evaluar el papel de la compañía en el mercado global de efectos asiáticos.

Palabras clave: Historia global, Comercio Asia y América, Navegación y guerra, Rio de la Plata

\section{PRESENTACIÓN}

Este ensayo observa la navegación de dos fragatas de la Real Compañía de Filipinas, la "Princesa de Asturias" y la "Santo Domingo de la Calzada", que en un arribo forzoso a Montevideo desde las rutas de Cabo de Buena Esperanza y del Cabo de Hornos inyectan al Rio la Plata de una enorme cantidad de efectos orientales de la India, China y Filipinas.

Este acercamiento, producto del azar de la navegación en tiempos de guerra y del lento pero persistente proceso de globalización comercial del consumo de Oriente, nos permite advertirlo como una palanca de acumulación para actores marginales a la Carrera de Indias, cuando aquella agonizaba bajo un modelo tardío de "comercio libre" marcado por la "dinámica imperial" de un mercantilismo tardío, en el ocaso del monopolio colonial. ${ }^{1}$

La globalización temprana, ya considerada una época crucial para el desarrollo del mercado moderno, nos permite observar cómo las economías distantes establecieron un régimen de conexiones transversales a los ordenamientos imperiales y generaron un tejido de relaciones que permitió la integración global de economía locales ${ }^{2}$. Esta observación

\footnotetext{
1 Delgado Ribas (2007, pp. 321-369).

2 Una apreciación del tema, desde la perspectiva latinoamericana, en Hausberger (2018, pp. 111-196) y Bonialian y Hausberger (2018, pp. 197-244). La búsqueda de una óptica americana no será posible, a nuestro parecer, si no logramos entender en la acción de los actores locales sus estrategias de integración global. Coincidimos, por ello, en el uso conceptual de "globalización arcaica” que le da Moutoukias (2018, 141-182) para explicar el contexto de inscripción americana.
} 
trata de advertir el impacto que produjo la súbita interrelación del Rio de la Plata con la circulación global de mercancías orientales, de la India y China, a través de la Real Compañía de Filipinas -un actor económico de interés monárquico, pero de agencia privada ${ }^{3}$.

Nos interesa destacar el papel de la agencia empresarial de la propia Compañía, como de los actores locales que movilizaron recursos, relaciones y sortearon el escenario de guerra externa e invasión interna para hacer negocios, a la vez que mostrar los altos costes que para la Compañía tuvo el adverso contexto y la fragilidad de sus recursos de competencia.

A través del "comercio de pacotilla" de su tripulación indagamos la canasta de mercancías que se despacharon desde Calcuta, Cantón y Filipinas para completar una amplia oferta de efectos de lujo y de consumo popular. Nos interesa distinguir y ordenar su oferta por calidades, precios, costes y costas de su circulación. La distribución interior, en un contexto de incertidumbre, es también relevante para conocer los polos de demanda y la estructura de la oferta en el sistema de circulación interior del virreinato del Rio de la Plata y sus conexiones externas, transandinas en el Alto Perú y Chile, Montevideo y el Brasil, así como el Litoral y Asunción del Paraguay.

La desigual suerte de los negocios para la Compañía y los actores locales nos sugiere el papel de las tensiones entre la comunidad local de intereses, la política imperial de libre comercio y la pérdida de hegemonía española en sus mercados coloniales, característicos de la "globalización arcaica" de la época.

El propósito de esta observación local se inscribe en una nueva lectura sobre las tramas de circulación de objetos, culturas de consumo y prácticas de negociación que marcaron la globalización comercial de fines del siglo XVIII y principios del XIX, en un contexto de enorme inestabilidad política y disputas militares enmarcadas en el ciclo de las revoluciones atlánticas. ${ }^{4}$

Sobre la mundialización de la plata americana Flynn y Giráldez (2014, pp. 29-76) y el enfoque crítico a la convergencia de precios Flynn y Giráldez (2008, pp. 359-387).

${ }^{3}$ En su estudio pionero Díaz-Trechuelo, concluye que con la Real Cédula de 12 de julio de 1803, la Compañía quedó "Remozada su estructura interna, ratificados sus privilegios, e incluso aumentados con nuevas gracias, se abrían para la Sociedad mayores horizontes y perspectivas de mejor fortuna. Pero muy pronto la guerra se encargaría de matar en germen sus esperanzas" Díaz-Trechuelo $(1965,98-110)$. Para una visión analítica del papel de la Compañía en el sistema comercial español ver Martínez Shaw (2007, pp. 36-42).

${ }^{4}$ Carmagnani (2004, pp. 118-187) y Carmagnani (2012); para el consumo europeo ver Pérez García (2017, pp. 1-68). 


\section{EL EPISODIO: DE CALCUTA Y CANTÓN A BUENOS AIRES}

La fragata "Princesa de Asturias" de la Real Compañía de Filipinas había salido de Calcuta el 4 de diciembre de 1804, recalado en Coringa y la costa de Coromandel "a completar su cargamento" desde donde daría la vela el 23 de diciembre de aquel año. En su travesía a Cádiz, al suroeste del Golfo de Guinea, había recibido noticias inquietantes de la fragata americana "Confianza" sobre el clima de guerra que la obligo a torcer su rumbo al suroeste, arribando tres meses más tarde al Rio de la Plata. ${ }^{5}$

Mientras tanto, en Madrid, los directores de la Compañía avisaban con optimismo al Ministro Soler que por medio del navío portugués "El Triunfo" se había tenido "noticia de la vela" que la "Princesa de Asturias" había dado el 9 de diciembre de 1804, cuando "salió con toda felicidad del Ganges (...) conduciendo un cargamento por valor en rupias de 603,559 que equivalen a cosa de 300 mil pesos fuertes", estimando que "a estas horas" estará de arribada en Canarias, si no ha tenido algún contratiempo, (...) en espera de comunicarle como presidente de la Compañía las más vivas ansias de anunciarle próximamente el salvamento de esta importante expedición"6.

Meses más tarde, el 27 de marzo de 1805, se notificó su entrada al puerto de Montevideo "con destino a Cádiz y registro de Calcuta" al mando del teniente de navío don Domingo Navarro, con una tripulación de 84 hombres, una capacidad de 430 toneladas y 12 cañones montados. La carga de la "Princesa" llegaba al estuario de Buenos Aires, en una flota de lanchas, el primero de mayo de 1805.

Francisco Antonio Letamendi, como comisionado segundo de la Real Compañía de Filipinas, había informado el 26 de abril de 1805, a don Ambrosio Funes, su socio comercial en Córdoba, del arribo de la fragata al puerto de Montevideo cargando 2,666 bultos o tercios, "desde Calcuta en la China" (sic), que venían consignados a don Martín de Sarratea, primer comisionado de la misma Compañía, y "que vamos a vender" .

${ }^{5}$ Su capitán declaró que el encuentro se produjo el 1 de marzo de 1805, que “...les aseguro la noticia de la Guerra, y que habían empezado las hostilidades... por cuyo motivo arribo a este Puerto sin otra novedad en su navegación." AGNU-Ex Archivo y Museo Histórico General, Capitanía Puerto, Libro 95, 1805-1818. ff. 24v-25. Agradezco a Luis Aguirre las referencias.

${ }^{6}$ Huizi, Lizaur y Gandásegui a Soler, Madrid, 1 de mayo de 1805. AGI Filipinas 991.

7 Ambrosio Funes fue un comerciante cordobés emparentado y favorecido por la familia de Tomás de Allende, que promovió su ascenso en los negocios. Hermano de Gregorio y Domingo, quienes ejercían una notable influencia religiosa en el clero regular- jesuitas y dominicos- y secular. Gregorio, el Deán Funes, fue un poderoso miembro del cabildo secular y promotor de la devoción de la Virgen del Rosario, que compartía en la Cofradía con Letamendi y el yerno de Sarratea, a la postre virrey de Buenos Aires, Santiago de Liniers: un lazo común muy importante para los negocios y la política del momento que nos ocupa. Ver Lida (2004, p. 192) y para la carta, Martínez Paz (1918, pp. 150-151). 
La fragata formaba parte de la segunda expedición enviada por la Compañía de Filipinas a la India, después de la paz de Amiens, con el expreso propósito de surtir de efectos asiáticos al comercio gaditano para el tráfico que "surtiera a la Nación" ${ }^{\text {. }}$

Casi tres meses después, el 20 de junio de 1805, recaló en el puerto de Maldonado la fragata "Santo Domingo de la Calzada" alías "Príncipe de la Paz", con la cargazón de la Real Compañía de Filipinas que había subido en Cavite y Cantón, entre diciembre de 1804 y febrero de 1805. El plan de navegación entre Cantón y Cádiz se trastornó también al tener noticia del estallido de la nueva guerra con Gran Bretaña ${ }^{9}$.

Resulta interesante la lectura del momento en la comunicación de los directores de la Compañía al ministro Soler, casi cuatro meses más tarde de la arribada a puerto de la fragata:

"En este mismo momento acabamos de recibir la plausible noticia de que la fragata de esta Compañía, "Santo Domingo de la Calzada", que salió de Cantón en 17 de febrero de este año con un rico cargamento de frutos y efectos de Filipinas y China, se ha asegurado en 28 de junio último en el puerto de Maldonado a la embocadura del Rio de la Plata, habiendo tomado la derrota para Montevideo su comandante don Juan Latre, Teniente de fragata de la Real Armada, por haber sabido en las inmediaciones de la Bahía de Tablas por un buque americano las hostilidades cometidas por los ingleses con los buques de guerra de SM, sin haber podido entrar en el puerto de Montevideo por la contrariedad de los vientos, aunque para el efecto hizo el comandante Latre, con los demás oficiales, los mayores esfuerzos por espacio de ocho días. No dudamos que se trasladaría el buque a Montevideo por haberse prestado aquel Gobernador a mariliar (sic) esta medida con las lanchas armadas en guerra, y confiadas al mando del Capitán de Navío de la Real Armada Don Santiago Liniers, operación precisa por presentarse diariamente en las cercanías de Maldonado, y cruzar a la recalada

8 "El mismo espíritu de poner en circulación útil los capitales de la Compañía surtiendo a la Nación de los frutos y géneros del Asia -explicaban sus directores al presidente-, nos ha hecho determinar con acuerdo de la misma Junta la expedición de la fragata, de este mismo cuerpo, "Princesa de Asturias" que en el próximo marzo deberá salir también del puerto de Cádiz para la costa de Coromandel" Carta de los directores Huizi, Lizaur y Gandásegui a Soler, 14 de febrero de 1804. AGI Filipinas 991.

9 Al mando venía el experimentado teniente de fragata don Juan Latre, quien había hecho varias navegaciones entre las Filipinas, Callao y el Rio de la Plata. En su hoja de servicio contaba varias expediciones al Mar del sur, el cruce de Cabo de Hornos, el reconocimiento de las Malvinas y no pocas acciones de guerra contra corsarios franceses, angloamericanos y portugueses: era un hombre de armas haciendo comercio para la Compañía. Maestro Castañeda (1998, pp. 433-441); Generelo Lanaspa (1998, pp. 337-347). Agradezco a este último, director del Archivo Histórico de Huesca, la generosa transmisión de los textos y referencias. Díaz-Trechuelo (1965, pp. 191-193). 
del Rio de la Plata una fragata inglesa de 38 cañones, un bergantín de 18, y una balandra de 14: todo lo cual realza la felicidad de la entrada de la Santo Domingo en Maldonado, aunque debida en parte a la vigilancia y destreza de Latre en dar caza por algún tiempo a los enemigos más débiles, y en huir oportunamente de los de mayor resistencia."10

La fragata arribó a puerto con una carga facturada en más de 242 mil pesos fuertes, dos terceras partes cargadas en Cantón, principalmente de tejidos, especiería y loza que habrían de inundar el mercado rioplatense y su radio de circulación continental ${ }^{11}$.

La noticia de ambos arribos y su buena empresa se conoció en Madrid el 20 de marzo de 1806, cuando se notificó a Soler que los "cargamentos estaban casi todos vendidos" ${ }^{12}$.

\section{EL STOCK DE MERCANCÍAS ASIÁTICAS: DE LA ABUNDANCIA EN PUERTO A LOS ALMACENES Y CIRCUITOS DEL INTERIOR}

Entre mayo y junio de 1805 el puerto de Buenos Aires se convirtió en el mayor depósito de efectos orientales del Atlántico sur. Entre las dos fragatas se dispuso de casi medio millón de pesos en mercancías, aforadas a precios de compra, que implicaba una rebaja sustancial respecto a lo que podían rescatar de sus ventas, respecto a las mercancías venidas de Lima.

En el caso de la primera en llegar al Rio de la Plata, la fragata "Princesa de Asturias", manifestó cargar hasta IBuenos Aires 1,737 piezas de comercio de Oriente, habiéndose averiado 13 de ellas en Montevideo y 27 del "comercio de pacotilla" de los 61 fardos de géneros favor de los "individuos del buque", que completaban con 2 baúles, 6 fardos por separado y dos "cajoncitos de loza". Allí mismo se registraron como carga lde Calcuta 1,249 fardos de géneros, inclusive 400 sacos de algodón hilado con valor equivalente a 100 de fardos; un baúl de hilados; diez atados de "dientes de elefantes"; mil paquetes de bejucos y 147 sacos de "clavos de comer". De Coringa, donde había hecho escala, se registraron 251 "fardos de géneros"13.

\footnotetext{
10 Huizi, Lizaur y Gandásegui a Soler, Madrid, 10 de octubre de 1805. AGI Filipinas 991.

11 Según consigna la relación de los bultos, cajones y sacos de varios efectos del Asia, facturados en Manila el 5 de diciembre de 1804 y en Cantón el 15 de febrero de 1805, el valor por cuenta y riesgo de la Real Compañía superaba los 81 mil pesos. AGNA IX-45-2-6.

12 Huizi, Lizaur y Gandásegui a Soler, Madrid, 20 de marzo de 1806. AGI Filipinas, 991

13 "Sobre el reconocimiento, confrontación y entrega a Don Martín Simón de Sarratea del cargamento que condujo la Fragata Española nombrada la Princesa, procedente de Calcuta de cuenta
} 
Si acudimos a los registros de Montevideo, al estuario de Buenos Aires se remitió lo sustancial de su carga: 1,653 piezas de comercio, 44 fardos de su tripulación, que bajo la denominación de "pacotilla" descargaron 71 piezas. Por cuenta de la Real Compañía de Filipinas el aforo de la cargazón sumaba 227,225 pesos 4 reales, equivalente a las 481,718 rupias en que se habían aforado en Manila y Coringa, a precios de compra, corriendo en calidad de pacotilla 14,203 pesos. En conjunto, la cargazón venia valuada en 241,240 pesos 4 reales, de los cuales el $6 \%$ representaba la de pacotilla. Era, pues, el puerto de Buenos Aires el objetivo más rentable de la negociación de su carga en la ya trastornada navegación ${ }^{14}$.

Siendo el puerto de Buenos Aires el centro de mayor consumo, por un movimiento de demanda que se había afirmado en la segunda mitad del siglo XVIII, "democratizando" el gusto por los efectos de China principalmente de ropa y sedas, como ha señalado Bonialian (2012), mayoritariamente venidos de Lima por los privilegios otorgados a los comerciantes de aquel puerto o por contrabando de franceses y arribadas desde el Brasil. Sin embargo, no se tenía noticia de una cargazón de tales dimensiones y valores que hubiera llegado con registro a la Aduana ${ }^{15}$.

A fines de abril de 1805, se trasladó la carga de la "Princesa de Asturias" a cinco lanchas y una balandra para encaminarla a la Aduana de Buenos Aires. Por los despachos que don Manuel de Ortega, agente de la Compañía en Montevideo, remitió a Sarratea la carga de la "Princesa de Asturias" se computaron por cuenta y riesgo de la ICompañía 1,814 fardos con géneros, algodón y seda; 247 sacos con algodón y clavo de comer; 995 atados y un baúl. De cuenta de pacotilla de la tripulación, 43 fardos y un baúl ${ }^{16}$.

Siendo mayoritariamente cargazón de la Real Compañía de Filipinas, sus comisionados en el puerto fueron los encargados de la descarga, depósito y más tarde su venta. Sobre ello, Francisco Antonio Letamendi se excusaba con su socio cordobés Ambrosio Funes, en carta del 27 de mayo, por demorar el envío de una custodia al Deán Funes, "por las graves ocupaciones con que me hallo de resulta del arreglo, y venta de los Géneros trahidos (sic) desde la India a Montevideo por la fragata "Princesa de Asturias"17

de la Real Compañía de Filipinas", Año de 1805. AGNA, XIII, 16-7-4; AGN Uruguay, Montevideo. Aduana de Capitanía de puerto, Año de 1805, no. 30, f. 25.

${ }^{14}$ Testimonio de Joaquín Proyet, administrador de la Aduana Buenos Aires, 1 mayo 1805. AGNA, XIII, 16-7-4. La razón de cambio consignada es de 220 rupias por 100 pesos de 8 reales.

${ }^{15}$ Jumar (2016, pp. 171-264) ha explicado la conformación del "complejo portuario rioplatense" como un complicado dispositivo que favoreció el transito legal del contrabando y las economías regionales El texto de referencia sobre el contrabando es de Moutoukias (1988). Ver Bonialian (2012, pp. 140-149).

16 AGNA, Bs. As, XIII 14-7-1.

17 Letamendi a Funes, 27 de mayo de 1805. Martínez Paz (1918, p. 152). 
Por su cuenta don Miguel Cayetano Soler, como presidente de la Junta General de Accionistas, informó en Madrid que la cargazón por cuenta y riesgo de la Compañía en la fragata "Princesa de Asturias" sumaba, en "valor de factura", 303,461 pesos 5 reales; mientras que la carga de la fragata "Santo Domingo de la Calzada" ascendía a 223,893 pesos 5 reales, por igual concepto. En conjunto, un valor superior a 527,354 pesos, 5 reales $^{18}$.

El propio Soler estimaba que a su arribo a Buenos Aires "devengaban entre derechos reales, fletes, seguros y otros gastos hasta" 642,896 pesos, 2 reales, de manera que puestos en plaza de venta tuvieron de "costo y costas a la Compañía" la suma de 1’157,169 pesos, 7 reales.

En ese mismo recuento, se notificó a los accionistas que la parte vendida por las noticias recibidas de su comisionado, don Martin de Sarratea, ascendió a 1'474,778 pesos, quedando en existencia al 31 de diciembre de 1805 efectos del cargamento de la "Princesa de Asturias" por 4,345 pesos 1 real y de la "Santo Domingo de la Calzada" por un valor de 102,498 pesos 7 reales "todo a coste y costas", sumando 106,844 pesos esperando compradores, incluso de algunos efectos de Europa quedados de "envíos antiguos" que ascienden a 108,625 pesos 4 reales.

En resumen, les explicó el ministro Soler, la "parte vendida de ambos cargamentos en el discurso de este Balance" ascendió a 1’474,778 pesos, "dejando una ganancia liquida" para la Compañía de 424,452, a una tasa neta de $28,7 \%$ sobre el valor estimado en puerto, pero a un $80,5 \%$ respecto a la facturación de origen, en ambos navíos: una tasa baja para ser realista, pero suficiente para enmendar las cuentas de la Compañía ante sus accionistas. Hasta aquí llegó el entusiasmo de la Compañía por los negocios. (cuadro 1).

\section{REGULACIÓN DE EXISTENCIAS, VALORES, COSTOS Y COSTAS DE LAS MERCANCÍAS ORIENTALES: LAS ESTRATEGIAS LOCALES}

Los testimonios sugieren que la mayor parte de la cargazón se habría vendido y almacenado en Buenos Aires, en espera de que la demanda subiera los precios, valorizando el stock que habría de promover muy buenos negocios. El propio Letamendi confesó a su socio Ambrosio Funes, que "el cargamento de la Compañía de Filipinas venido de Calcuta en la India, (lo) vendí a un sujeto de este Comercio" En esa misma fecha, el informante se complace de su fortuna:

18 Las cantidades en el original están en reales de vellón, que hemos convertido a pesos fuertes: usamos la equivalencia, a razón de 20 reales de vellón por peso. 


\section{CUADRO 1}

Valores de la carga de las fragatas Princesa de Asturias y Santo Domingo de la Calzada, según estimaciones de la Real Compañía de Filipinas, 1807

\begin{tabular}{|c|c|c|c|}
\hline $\begin{array}{l}\text { VALORES DE LA } \\
\text { CARGA }\end{array}$ & $\begin{array}{l}\text { VALORES } \\
\text { reales de vellón }\end{array}$ & $\begin{array}{l}\text { VALORES } \\
\text { pesos de a } 8\end{array}$ & $\begin{array}{l}\text { INCREMENTOS } \\
\% \text { sobre factura }\end{array}$ \\
\hline $\begin{array}{l}\text { Valor de factura de } \\
\text { ambas fragatas }\end{array}$ & $10,547,091$ & $\$ 527,354$ ps. 4 rs & \\
\hline $\begin{array}{l}\text { Valor con derechos } \\
\text { reales, fletes, } \\
\text { seguros y otros } \\
\text { gastos }\end{array}$ & $12,857,925$ & $\$ 642,896$ ps. 2 rs & $122 \%$ \\
\hline $\begin{array}{l}\text { Valor puestos en } \\
\text { Buenos Aires a } \\
\text { "costo y costas" }\end{array}$ & $23,143,396$ & $\$ 1,157,169$ ps. 7 rs & $219 \%$ \\
\hline $\begin{array}{l}\text { Ventas de ambos } \\
\text { cargamentos }\end{array}$ & $29,495,558$ & $\$ 1,474,778$ ps. & $280 \%$ \\
\hline Ganancia liquida & $8,489,039$ & $\$ 424,452$ ps. & $80 \%$ \\
\hline $\begin{array}{l}\text { Existencias de } \\
\text { Princesa de } \\
\text { Asturias a "costo } \\
\text { y costas" }\end{array}$ & 86,901 & $\$ 4,345$ ps. 1 rs & $1 \%$ \\
\hline $\begin{array}{l}\text { Existencias de S } \\
\text { Domingo de la } \\
\text { Calzada a "costo } \\
\text { y costas" }\end{array}$ & $2,049,977$ & $\$ 102,498$ ps. 7 rs & $19 \%$ \\
\hline $\begin{array}{l}\text { Existencias al } 31 \text { de } \\
\text { diciembre de } \\
1805 \text { ambas } \\
\text { fragatas }\end{array}$ & $2,136,878$ & $\$ 106,844$ ps. & $20 \%$ \\
\hline $\begin{array}{l}\text { Efectos de Europa } \\
\text { de envios } \\
\text { antiguos }\end{array}$ & $2,172,509$ & 108,625 ps. 5 rs & \\
\hline
\end{tabular}

Fuente: AGI/ Filipinas, 911.

“... tenemos otra Fragata nombrada el Santo Domingo que ha arribado a Maldonado procedente de la China, propia de la misma Compañía, cuyo cargamento esperamos aquí en estos días: Trae muchísimos Mahonés, Pimienta, Canela, Té y otras cosas que deben producir acaso más que el otro cargamento. La Providencia 
me favorece más de lo que merezco, con unas entradas, que no esperaba."19

El entusiasmo del comisionado tenía fundamento, ya que la carga de ambas fragatas habría de inyectar al comercio de Buenos Aires de una inesperada oferta y supliría la costosa demanda que desde Lima se satisfacía en tiempos regulares; por ello la distribución desde el puerto para su territorio interior fue significativa en sus beneficios y circuitos de circulación.

En otra comunicación de Letamendi a Funes, del 26 de septiembre de 1805 , anota una serie de importantes consideraciones sobre el impacto de la oferta de efectos orientales, pero también sobre su papel en el mercado local:

"Los géneros conducidos por la Fragata de la Real Compañía nombrada Santo Domingo, se han vendido ya en la mayor parte a precios que no esperaba, y como habiendo comprador por mayor no está en mi mano la segregación de ninguna porción de aquel renglón, no tengo arbitrio para poder deliberar en el particular a menos que pidiéndoles a los compradores con los plazos que estipulen convengan sobre los precios, y para esto debía estar aquí el Paisano Echeverría, sin cuya presencia no es posible que me atreva a nada"20

El testimonio es muy interesante, ya que da cuenta de varios tópicos sobre los cuales merece detenerse: uno de ellos, el más relevante a nuestro parecer, se refiere al acopio de mercancías y las expectativas de los precios a futuro, que probablemente indujo a los comerciantes locales a comprar al por mayor; segundo, que los precios debieron haber sido inusualmente favorables a la Compañía, pero más atractivos a los compradores respecto a la costumbre de traer desde Lima los efectos orientales; por otra parte, dado el carácter confidencial de la carta, se asoma el vínculo discrecional entre el comisionado y un comerciante del Interior. El tema de su interés era conocer los precios en Buenos Aires, para regular la oferta en Córdoba. El paisano Echeverría, como comerciante, podría realizar operaciones que el cauto Letamendi no se atrevía a averiguar, pero quizá favorecer.

Cuestión de la mayor importancia está en resolver la relación entre los valores de dicha cargazón a costos de plaza de la carga, el coste del viaje, costas y seguros, así como los derechos devengados para la Corona, porque

19 Letamendi a Funes, 25 de julio de 1805. Martínez Paz (1918, p. 152). Y es que la fortuna de nuestro testigo se relacionaba con que había "firmado compañía con este Señor Don. Martin de Sarratea por ocho años contados desde el $1^{\circ}$ de Abril próximo pasado, según contrata firmada por ambos". Martínez Paz (1918, p. 131).

${ }^{20}$ Letamendi a Funes, 26 de septiembre de 1805. Martínez Paz (1918, p. 157). 
de allí se deriva el beneficio para la Compañía y los costes en plaza de venta que constituyen el mínimo de los precios en que se expedirán en América.

Una primera dificultad se deriva de la propia fuente, ya que las facturas de carga se expresan en valores de las mercancías en sus puertos de salida y sus monedas de cambio, en el caso de la India en rupias y en reales de vellón para Cantón. Sin embargo, la razón de cambio contable entre estas monedas locales y de cuenta con el peso de a ocho reales es resuelta por el hecho de que, para entonces, los pesos fuertes de la Corona acuñados en América ya tenían una amplia circulación global y constituían referencia de todos los actores ${ }^{21}$.

Una segunda dificultad, atiende a la conversión de los precios en valores de pesos fuertes a moneda corriente de la tierra. El examen de las guías revisadas nos indica una estructura de esta complejidad. Tomemos un ejemplo: en la guía que se destinan a Córdoba 342 sanas Jalalpore, a nombre de Dámaso José Gómez, se asienta un valor de la mercancía en 1,290 pesos fuertes 4 reales, considerando la factura de origen, para posteriormente tasar en "pesos corrientes de América", equivalentes a 128 cuartillos es decir 15 reales de vellón, por un valor de 1,713 pesos 5 reales, a partir de cuya estimación se establece la alcabala de venta y con ello el valor de plaza, que alcanza en este caso 3.420 pesos "corrientes". Esta estimación se repite en las guías y sólo varía de acuerdo con la calidad de los efectos y la distancia de los mercados ${ }^{22}$.

Una tercera dificultad, que se expresa ocasionalmente en las facturas y los despachos, es la divergencia entre los valores facturados y los valores en plaza a los que se estima su venta. Debe recordarse que estamos siguiendo la ruta en documentación de la Compañía y no en la contabilidad fiscal, además de que la propia Compañía gozaba de privilegios en tiempo de guerra, según la Real orden de 20 de julio de 1793 y refrendada en la Nueva cédula de 1803, que habilitó para el comercio directo con América y liberó de derechos a la tripulación solo pagando la alcabala en los lugares de introducción de la carga. En nuestro caso, el $4 \%$ más cuatro reales del "ramo de tierra o eslingaje" y el costo de guías para su internación.

Finalmente, una complejidad adicional se deriva del carácter compuesto del beneficio entre aquel correspondiente a la Real Compañía, el de los factores y comisionados, como el de los compradores y las divergencias de precios entre plazas de compra, plazas de descarga y lugares de venta. Si bien las facturas nos proporcionan información puntual de los precios en plazas de venta, la razón de cambio añadiendo "costas y costes",

21 Una muy documentada explicación de valores y equivalencias en Muñoz Serrulla (2015), que da seguimiento a disposiciones de acuñación y valores de circulación.

22 AGNA Bs As, XIII 4-1-11, libro 2256, foja 358. 1 de febrero de 1806. 
más la cuota de ganancia es un problema muy complejo para resolver aquí con la información disponible, pero hay alternativas.

En este caso, habremos de recurrir a las estimaciones hechas por la Junta de Gobierno a los accionistas de la propia Compañía, en el Informe a la Junta general, realizada el 24 de julio de 1807, donde se habló muy detenidamente sobre los beneficios, costes y contratiempos de las navegaciones que nos ocupa. Para sus cálculos acuden a reales de vellón, en tanto constituye la moneda de cuenta que permitía homogeneizar los valores ${ }^{23}$.

Pongamos, entonces, atención en algunos elementos importantes de la contabilidad: primero, el valor del embarco en las plazas de origen -en nuestro caso Calcuta, Manila y Cantón- respecto a la descarga en el puerto de Buenos Aires, como destino imprevisto pero lucrativo, tuvieron un incremento global neto del $80 \%$ sobre su valor facturado, todo en moneda de cuenta; segundo, que los derechos, fletes, seguros y otros gastos, representaron un $116 \%$ de su valor facturado; tercero que considerando "costes y costas" representaron, globalmente, un incremento del más del 200\% respecto a los valores de factura de partida; cuarto, que el beneficio neto para la Compañía por las ventas globales de 29 millones sumó casi el $30 \%$ del expendio y el $66 \%$ de valor a la entrada en el puerto de Buenos Aires, lo que representó una tasa de beneficio mayor al 100\% entre la entrada y la venta de efectos.

Hay que considerar, entonces, que los beneficios del comercio de efectos de China y la India para los comerciantes de Buenos Aires, al poner en distintas plazas las cargazones de ambos navíos, deberían rondar una proporción semejante. Por tanto, podemos aproximarnos con criterios válidos a estimar en un múltiplo de tres el incremento de los valores facturados a su venta en Buenos Aires.

\section{EL "COMERCIO DE PACOTILLA": MICRO-OBSERVACIÓN DE GÉNEROS, PRECIOS Y ESTRUCTURA DE OFERTA}

Entre los privilegios otorgados a la Compañía, por Real Cédula de 1803, se confirmó para tiempos de paz la excepcionalidad de tiempos de guerra, relativa a que los mandos de la tripulación trajeran consigo géneros de su interés en la cargazón para su expendio, sin costo y costas de transporte y solamente obligados a pagar alcabala y derechos de desembarco en los puertos. La medida obedeció al interés por reclutar oficiales de la Real Armada, con experiencia y capacidad de sortear peligros y garantizar los

23 AGI, Filipinas, 991. Ver Muñoz Serrulla (2105, pp. 137-149). 
arribos a puerto, añadido a su interés el beneficio de su carga en las negociaciones ${ }^{24}$.

En la Junta de Gobierno de la Compañía, celebrada en Madrid el 10 de febrero de 1804, se abordó la propuesta para regular el "comercio de pacotilla" de la tripulación, particularmente de los navíos que van de la costa de Coromandel, Bengala, China y Filipinas a Lima, por lo cual se elaboró el Plan de Pacotillas, enfatizándose la urgencia de una resolución:

“...con el (pago) de los sueldos que deben gozar los comandante y demás oficiales en los viajes respectivos, le pareció (a la Junta, AI) que no debía diferir por más tiempo la formación de uno de estos Arreglos, que la concesión de Pacotilla, tiene por objeto interesar en el éxito de las expediciones a los que directa e indirectamente pueden influir en el con proporción a la parte que puede tener cada Individuo en verificar pronta y felizmente la navegación a viajes de ida y vuelta, no dudándose que el agente más poderoso en los hombres para excitar su actividad y celo es el de su propio interés" ${ }^{25}$

El Reglamento habría de beneficiar al primer viaje que realizo la fragata "Santo Domingo de la Calzada", desde Cádiz a la costa de Coromandel, que precedió a su navegación de Calcuta hacia el Río de la Plata. Nos vamos a detener en analizar la "carga de pacotilla", para establecer algunos criterios de interpretación sobre el impacto de la arribada.

El microanálisis de la "pacotilla" de las tripulaciones también nos arroja información sobre los beneficios de la navegación, pero sobre todo nos da cuenta de los productos menudos que se internan a las bodegas y se pondrán en circulación más tarde. En todos ellos interviene el comisionado de la Compañía en Buenos Aires, Martin de Sarratea, por mano y actuación de su dependiente Francisco Letamendi. Nuestras fuentes son las facturas que hicieran los factores de la propia Compañía de Filipinas en Manila, don Celedonio Latreita y don Rafael Lizaur, así

${ }^{24}$ Sobre los privilegios otorgados en la Real Cédula de 1803, véase Díaz-Trechuelo (1965, pp. 97-110).

${ }^{25}$ En la propuesta se establecen los siguientes criterios: 1. Conceder valores máximos, "libres de fletes", al comandante y primer piloto hasta por 6 mil pesos; al segundo id y piloto $1^{\circ}$ hasta por 3 mil; al segundo y hasta al cuarto ídem mil quinientos; al cirujano y al contramaestre mil por cada uno; al carpintero $1^{\circ} \mathrm{y}$ al calafate quinientos; al Maestre, cuando lo hubiere, igual que al $2^{\circ}$ comandante, tres mil; 2. Los efectos deben venir "en los alojamientos respectivos ... y de ningún modo en escotillas para evitar todo fraude"; 3. Deberá hacerse factura de los efectos, salvo los de Filipinas, para que "sirva para el despacho" y decomisados los no registrados y castigados los responsables. AGI Ultramar 640. 
como del comisionado en Cantón. En el caso de las facturas venidas de Calcuta, fueron elaboradas y signadas por el factor de aquel enclave. ${ }^{26}$

Las cargas provenientes de Filipinas, Calcuta y Cantón incluían por lo menos cinco grandes ramos de efectos: textiles y mantas de algodón; tejidos y estampados; ropas de seda; especiería y artículos de loza, marfil y nácar además de "curiosidades", que van desde abanicos y alfileteros hasta libros de costumbres y castigos chinos.

Para la factura de la fragata "Princesa de Asturias", el comandante y su tripulación descargaron en Buenos Aires efectos de la India por más de 11 mil pesos, equivalente a 23,261 rupias: allí registraron telas y estampados (elefantes, cotonías, chitas, mamudíes y baftas), pero también distintos tipos de muselinas. Complementariamente, en la ropa traída había trajes bordados, lujosos y modestos, camisas y pañuelos (cuadro 2).

En sus bodegas, la fragata "Santo Domingo de la Calzada" condujo en fardos una serie de efectos que fue posible distinguir en las guías de Manila y Cantón. Allí también se pueden dividir tres grupos de efectos por su origen y clase: primero, textiles de la India como elefantes, salampuris y mantas; terlingas y mantelería de Ilocos, en el archipiélago filipino; pañuelos y medias seda de Huanpú -Wampú en la fuente- desde la costa cantonesa. Complementa la carga descrita, con especiería de clavo hindú y pimientas del archipiélago filipino de Tayabas, Camarines, La Laguna y Batangas (cuadro 3).

De los más de catorce mil pesos en que aforaron el comercio de pacotilla de la fragata "Princesa de Asturias", el comandante Navarro cargó 5,843 pesos 7 reales, equivalente al $41 \%$ del total, habiendo dejado en Montevideo un $25 \%$ de la carga y puesta en Buenos Aires el resto por valor de 4,360 pesos 3 reales. De manera semejante, el segundo comandante, Miguel Villodas, que cargo 1,986 pesos 2 reales y vendió el 44\% en el estuario mientras el maestre, Rafael de María, que cargó 2,883 pesos llegó a puerto con $81 \%$ para su venta, así como el cirujano, los pilotos $3^{\circ}$ y $4^{\circ}$, el calafate y el carpintero. La distribución de 43 de los 62 fardos, farditos, baúles y cajoncitos permite asegurar que fue preferentemente destinada a Buenos Aires, distribuida en correspondencia a sus valores (Apéndice cuadros A1 y A2).

La tripulación de la "Santo Domingo de la Calzada", por su parte, llegó a puerto con casi 15 mil pesos de efectos de pacotilla: el $40 \%$ de su comandante, Juan Latre, y con su segundo y el maestre bajaron el $80 \%$ de su carga. Es interesante señalar que mayoritariamente cargaron más de dos terceras partes con tejidos y el resto en loza, mercería y especiería. Las

26 La factoría de Calcuta se estableció en 1797 “al comenzar el comercio directo entre la India y España", según el permiso concedido en 1790 para hacer tráfico directo con dos factores permanentes. y en 1818 "fue creada una sucursal en la Costa de Coromandel" Díaz-Trechuelo (1965, p. 179) 


\section{CUADRO 2}

Factura general de los efectos de Asia que, en calidad de pacotilla embarcados en la Fragata Princesa de Asturias, de la Real Compañía de Filipinas, Buenos Aires 1 de mayo de1805

\begin{tabular}{|c|c|c|c|c|}
\hline RAMOS & PIEZAS & $\begin{array}{l}\text { VALOR } \\
\text { en rupias }\end{array}$ & $\begin{array}{l}\text { VALOR } \\
\text { en pesos.reales }\end{array}$ & CARGA $\%$ \\
\hline TEXTILES & & & $\$ 10,327.375$ & $92.7 \%$ \\
\hline Garras & 1451 & 5875.5 & $\$ 2,771.875$ & $24.9 \%$ \\
\hline Mamudíes & 739 & 4705.7 & $\$ 2,219.750$ & $19.9 \%$ \\
\hline Baftas & 1095 & 4608.3 & $\$ 2,174.125$ & $19.5 \%$ \\
\hline Casas & 254 & 2411 & $\$ 1,180.125$ & $10.6 \%$ \\
\hline Doreas & 59 & 334.6 & $\$ 158.125$ & $1.4 \%$ \\
\hline Elefantes & 20 & 306.2 & $\$ 144.875$ & $1.3 \%$ \\
\hline Cotonías & 13 & 55.6 & $\$ 26.375$ & $0.2 \%$ \\
\hline Chitas & 15 & 28 & $\$ 13.750$ & $0.1 \%$ \\
\hline Muselinas & 229 & 2751.4 & $\$ 1,307.750$ & $11.7 \%$ \\
\hline Otros tejidos & 75 & 706.12 & $\$ 330.625$ & $3.0 \%$ \\
\hline ROPA & & & $\$ 810.000$ & $7.3 \%$ \\
\hline Pañuelos & 311 & 1287.4 & $\$ 612.500$ & $5.5 \%$ \\
\hline Camisas & 54 & & $\$ 106.750$ & $1.0 \%$ \\
\hline Trajes & 29 & 191.2 & $\$ 90.750$ & $0.8 \%$ \\
\hline LOZA & & & $\$ 7.500$ & $0.1 \%$ \\
\hline $\begin{array}{l}\text { Juegos de té y } \\
\text { café }\end{array}$ & 2 & & $\$ 7.500$ & $0.1 \%$ \\
\hline SUMAS & & $23,261.02$ & $\$ 11,144.875$ & $100.0 \%$ \\
\hline
\end{tabular}

Fuente: AGNA, Bs. As. XIII 16-7-4. Nota: Los valores están en pesos fuertes y reales decimalizados.

curiosidades de "juegos de marfil", cuchillería y libros de arte ilustrados también tuvieron demanda. (Apéndice cuadros A3 y A4).

Resulta interesante contrastar la canasta de efectos traídos por el comandante, en un amplio arco que incluía sedas, rasos, loza fina y vajillas, además de "curiosidades" como fichas de nácar, abanicos y peines de marfil, canutillos, alfileteros, cajitas de nácar y carey para tabaco. En 
CUADRO 3

Factura de los bultos, cajones y sacos de varios efectos del Asia cargados por la fragata Santo Domingo de la Calzada en Manila 5 de diciembre de 1804 y Cantón 15 de febrero de 1805

\begin{tabular}{|c|c|c|c|c|c|c|}
\hline MERCANCIAS & BULTOS & $\begin{array}{l}\text { Piezas } \\
\text { de } 8 \text { varas }\end{array}$ & $\begin{array}{l}\text { VALOR } \\
\text { de compra }\end{array}$ & $\begin{array}{l}\text { Costo flete } \\
\text { y alijos }\end{array}$ & $\begin{array}{l}\text { Comisión } \\
\text { factores }\end{array}$ & $\begin{array}{l}\text { VALOR } \\
\text { facturado }\end{array}$ \\
\hline TEXTILES & & & & & & \\
\hline Elefantes $^{\mathrm{a}}$ & 140 & 4098 & $\$ 22,039.000$ & $\$ 215.875$ & $\$ 445.000$ & $\$ 22,699.875$ \\
\hline Salampuris ${ }^{\mathrm{a}}$ & 70 & 3476 & $\$ 10,863.500$ & $\$ 102.875$ & $\$ 219.250$ & $\$ 11,185.625$ \\
\hline Pañuelos ${ }^{\mathrm{a}}$ & 4 & 3331 & $\$ 21,017.000$ & $\$ 26.500$ & $\$ 420.750$ & $\$ 21,464.250$ \\
\hline Clavo especiería & 74 & 6807 & $\$ 484.500$ & $\$ 6.500$ & $\$ 9.750$ & $\$ 500.750$ \\
\hline $\begin{array}{l}\text { Terlingas de } \\
\text { Ilocos }^{\mathrm{b}}\end{array}$ & 56 & 4837 & $\$ 11,620.500$ & $\$ 229.375$ & $\$ 355.500$ & $\$ 12,205.375$ \\
\hline $\begin{array}{l}\text { Mantelería de } \\
\text { Ilocos }\end{array}$ & 42 & 3629 & $\$ 10,623.000$ & $\$ 200.375$ & $\$ 324.625$ & $\$ 11,148.000$ \\
\hline $\begin{array}{c}\text { Mantas regulares } \\
\text { para embalaje }\end{array}$ & & & $\$ 147.000$ & $\$ 2.125$ & $\$ 4.375$ & $\$ 153.500$ \\
\hline Total & 386 & 26,178 & $\$ 76,794.500$ & $\$ 783.625$ & $\$ 1779.250$ & $\$ 79,357.375$ \\
\hline SEDAS & Cajones & Pares & $\begin{array}{l}\text { VALOR } \\
\text { de compra }\end{array}$ & $\begin{array}{l}\text { COSTO flete } \\
\text { y alijos }\end{array}$ & $\begin{array}{l}\text { COMISION } \\
\text { factores }\end{array}$ & $\begin{array}{l}\text { VALOR } \\
\text { Facturado }\end{array}$ \\
\hline $\begin{array}{l}\text { Medias de seda de } \\
\text { Wampu }^{\mathrm{c}}\end{array}$ & 2 & 960 & $\$ 1,320.000$ & $\$ 6.750$ & $\$ 52.750$ & $\$ 1,379.500$ \\
\hline ESPECIERIA & Sacos & Arrobas & $\begin{array}{l}\text { VALOR } \\
\text { de compra }\end{array}$ & $\begin{array}{l}\text { COSTO flete y } \\
\text { alijos }\end{array}$ & $\begin{array}{l}\text { COMISION } \\
\text { factores }\end{array}$ & $\begin{array}{l}\text { VALOR } \\
\text { Facturado }\end{array}$ \\
\hline
\end{tabular}




\begin{tabular}{|l|l|l|l|l|l|l|}
$\begin{array}{c}\text { Pimienta de } \\
\text { Tayabas }^{\mathrm{b}}\end{array}$ & 96 & 384 & $\$ 191.750$ & $\$ 210.500$ & $\$ 30.000$ & $\$ 432.250$ \\
\hline $\begin{array}{c}\text { Pimienta de La } \\
\text { Laguna }^{\mathrm{b}}\end{array}$ & 16 & 64 & $\$ 133.500$ & $\$ 17.375$ & $\$ 4.500$ & $\$ 155.375$ \\
\hline $\begin{array}{c}\text { Pimienta de } \\
\text { Camarines }\end{array}$ & 12 & 48 & $\$ 87.500$ & $\$ 24.625$ & $\$ 3.250$ & $\$ 115.375$ \\
\hline $\begin{array}{l}\text { Pimienta de } \\
\text { Batangas }\end{array}$ & 6 & 24 & $\$ 44.500$ & $\$ 11.250$ & $\$ 0.875$ & $\$ 56.625$ \\
\hline Total & 130 & 520 & $\$ 457.250$ & $\$ 263.750$ & $\$ 38.625$ & $\$ 759.625$ \\
\hline TOTALES & & $\$ 80,138.50$ & $\$ 1,054.125$ & $\$ 1,268.625$ & $\$ 81,496.625$ \\
\hline
\end{tabular}

Fuente: AGNA, Bs. As. IX-45-2-6. Notas: Los valores están en pesos fuertes y reales decimalizados. (a) 2\% de comisión de los factores; (b) 3\% de comisión de los factores; (c) 4\% de comisión de los factores. 
contraste, los miembros de menor rango en la tripulación pusieron sus modestos intereses en transportar sedas de China, específicamente ropa de Nankín y alguna loza para servicio de mesa, para tomar té y café. El contraste nos señala la importancia que para todos los tripulantes tenían los "nanquines", como el efecto de mayor demanda y de venta segura. (Apéndice cuadros A5 y A6).

Si bien la tripulación de la fragata "Santo Domingo" había hecho en Cantón su comercio de pacotilla, en la fragata "Princesa de Asturias" se decidieron por traer mantas y tejidos de la India, que tenían buen mercado en sectores populares o como insumos estampados para confección de ropas. Así se desprende de la carga que acompañaba a su comandante que amparaban las 2,461 piezas de tejidos, por un valor cercano a los 6 mil pesos, que incluían baftas, sanas, garras y mamudíes de distintas medidas, pero visiblemente más baratos que las sedas chinas traídas por su colega de la fragata "Santo Domingo". En cierto sentido, los detalles dan testimonio de la complementariedad de los consumos y del arco de precios que caracterizaron a los efectos de Oriente, tanto para el consumo suntuario como popular, así como insumos de costura que vinieron a suplir con su arribo (Apéndice cuadro A7).

El consumo de efectos orientales, que resultaba de una combinación entre el gusto por lo exótico y la comodidad de sus precios, nos sugiere que las conexiones con Asia fueron muy dilatadas a lo largo del siglo XVIII y tuvieron un episodio crucial con el arribo de las fragatas de la Compañía, orilladas por la incertidumbre, pero también por la oportunidad de hacer negocios en los márgenes del Imperio $^{27}$.

\section{LA CIRCULACIÓN INTERIOR DE MERCANCÍAS ASIÁTICAS: CLAVES DE UNA INTEGRACIÓN TERRITORIAL DE LOS MERCADOS}

Según estimaciones de la Junta de Gobierno de la Compañía, contra las facturas revisadas, el valor de carga de la fragata "Princesa de Asturias" se facturó 227,225 pesos 4 reales, por tanto, la "Santo Domingo de la Calzada" debió cargar 300,119 pesos. Estas referencias son importantes para estimar la proporción de lo despachado desde el puerto de Buenos

\footnotetext{
27 "El gusto por las curiosidades y objetos de arte asiáticos llega a los coleccionistas porteños: ... En tiendas y casas particulares encontramos platos, tazas y tazones de porcelana, telas de zaraza, pequín, raso o listados, abanicos, quimonos y pañuelos fabricados en China. La moda era tan influyente que a falta de productos genuinos se los reemplazaba por imitaciones que remedaban las características de los salidos de los obradores de China” Mariluz Urquijo (1984, p. 19).
} 
Aires al territorio interior, según guías documentadas en los meses sucesivos a su arribo ${ }^{28}$.

Hasta aquí los testimonios nos describen el arribo y desembarco de efectos de la India y China, aunque nos dejan en vilo sobre el problema de la circulación interior, esencial para nuestro argumento, ya que de allí se desprende alguna lectura sobre el radio de la distribución y las estrategias de negociación de los comerciantes porteños, sus relaciones con socios y comisionados, así como los efectos de mayor consumo en los distintos polos de demanda.

Es importante recordar que a la llegada de las fragatas se estaba viviendo el momento de fortalecimiento del puerto de Buenos Aires, en el contexto del amplio espacio peruano, desplazando a Lima como centro abastecedor de importaciones y canal de exportación de platas. Es gracias al dinamismo del Interior orientado a la demanda minera del espacio altoperuano, al mercado transandino chileno y la circulación de yerba mate y ganados por el Litoral que las regiones interiores cobran enorme importancia. El papel de Buenos Aires, como gran centro de consumo e introductor de importaciones reforzará este esquema organizacional de los mercados. ${ }^{29}$

Una primera aproximación nos permitió advertir que, entre mayo de 1805 y octubre de 1806, momentos previos a la primera invasión inglesa y su derrota, las fragatas "Princesa de Asturias" y "Santo Domingo" despacharon desde Buenos Aires guías por un valor facturado mayor a $54 \mathrm{mil}$ pesos de 8 reales: 40 mil la primera y más de 14 mil la segunda (Apéndice cuadro A8).

Es interesante señalar que el mayor flujo se dio hacia el Atlántico, por el puerto de Montevideo, en un movimiento pendular de arribo y redistribución, que ya nos advierte sobre el posible trasiego de efectos orientales al circuito luso-montevideano. En cualquier caso, los más de catorce mil pesos despachados son significativos como polo de demanda e integración inter-portuaria, que representaron el 26\% del total despachado.

Otros puntos del espacio rioplatense, como Potosí y Chuquisaca en Charcas, resultan relevantes por sus conexiones distantes, así también la capitanía de Chile y sus conexiones andinas. En el caso chileno sumaron

${ }^{28}$ Debe notarse que las cifras, en reales de vellón, difieren de lo estimado por Soler en su Informe a la Junta general, donde la información es poco consistente ya que responde más al interés contextual de su enunciación, que a la propia contabilidad.

29 "Buenos Aires como capital del virreinato, con sus funcionarios, también era importante nudo de tránsito y centro de consumo. Punto de exportación de cueros y de introducción de efectos europeos y esclavos que distribuían en un amplio espacio que llegaba hasta la zona minera andina, el Paraguay, el Interior, Cuyo, Santiago de Chile y la costa del Pacífico, en un proceso de franco desplazamiento de los mercados limeños" Assadourian y Palomeque (2014, p. 47). Aquí seguimos la caracterización del espacio peruano tardío que hacen Assadourian y Palomeque (2014, pp. 37-58). 
más de seis mil pesos, con un importante cargamento de clavo especie, mientras que, hacia el norte minero, textiles por casi seis mil pesos. Considerando los polos de demanda de Salta, con casi un décimo del total y Córdoba, con el $11,5 \%$, en conjunto sumaron más de once mil $\operatorname{pesos}^{30}$.

$\mathrm{Si}$ pensamos la circulación en términos de circuitos, o ejes de integración en rutas de larga distancia, pueden advertirse una mayor significación. Así, la ruta interior hacia el espacio altoperuano que vincula Córdoba (11\%), el eje tucumano -que incorpora a Catamarca y Santiago del Estero- (17\%), con Salta y Jujuy (13\%), nos arroja un $41 \%$ del valor de lo despachado por ambas fragatas. ${ }^{31}$ Si añadimos lo remitido al Alto Perú, Potosí y Chuquisaca (10\%), estamos considerando más de la mitad del total de efectos orientales remitidos desde Buenos Aires.

En menor escala, pero muy significativo por los encuadernamientos regionales que representaba en el Litoral, es la distribución por San Nicolás de los Arroyos, Santa Fe -como bisagra entre el Interior y el Litoral-, Corrientes y Asunción del Paraguay a donde fue a parar un décimo de los efectos orientales ${ }^{32}$ (Apéndice cuadro A9).

En general, puede estimarse que en el tendido de las rutas de distribución las corrientes de efectos orientales promueven el flujo inverso de metales, activan el crédito mercantil y complementan la producción de textiles regionales que, en ese momento, tropezaban con una crisis de oferta.

Muy probablemente la entrada masiva de textiles de algodón, a precios cómodos y con buenas utilidades al comercio, fortalecieron la tendencia a la popularizaron del consumo de tejidos importados. Es posible que el

${ }^{30}$ Ya en su investigación sobre el comportamiento de las importaciones ultramarinas de Córdoba, Assadourian y Palomeque (2001, pp. 5-8). nos previenen sobre el peso fundamental de los textiles de algodón, sobre lana, lino y seda.

${ }^{31}$ Sobre Córdoba, Halperin (1972, p. 22) “Aquí -en Córdoba- la ruta peruana entra por fin en el Litoral. Esa ruta y sus tráficos son los que han hecho nacer a ese sector oriental del Interior (...): cada vez más el interior mercantil es intermediario entre el Perú y el puerto atlántico (de Buenos Aires); el comercio más la exportación y exportación de los productos locales es dejada en segundo plano; el comercio libre es en parte responsable de la aceleración de ese proceso”. Sobre Tucumán, Halperin (1972, p. 19) "La ciudad de Tucumán es centro vital de la ruta entre Buenos Aires y el Perú; un próspero grupo de mercaderes debe su riqueza a este hecho decisivo" Sobre Salta, Halperin (1972, pp. 16-17). "Sobre una plebe mestiza (...), gobierna una aristocracia orgullosa y rica, que da a la ciudad de Salta un esplendor desconocido en el resto del Rio de la Plata. (...) Esa aristocracia señora de la tierra domina también el comercio salteño"

32 "Estos centros -nos dice Halperin (1972)-, aparte del más antiguo de todos, el de Asunción que seguirá a partir de 1810 su órbita propia, son tres: Corrientes, en el norte allí donde el Paraguay junta sus aguas con el Paraná; Santa Fe, en la orilla derecha de este río, a mitad de camino entre el Plata y los centros norteños, y Buenos Aires, erigida allí donde, muy cerca del nacimiento del vasto río, las colinas reemplazan a la costa pantanosa de su margen derecha" (pp. 27-28) Para una documentación de las vinculaciones del área con Buenos Aires y sus capacidades exportadoras compensatorias de su consumo, véase Wenzel (1988). 
efecto en regiones de tejedores como Santiago del Estero, "una Galicia americana" diría Halperin (1972), haya sido devastador y en la sierra cordobesa, "una tierra de inmigración", donde solía practicarse el Putting-out System de la tejeduría haya promovido la confección de ropas. En cualquier caso, es un tema para indagar con mayor detalle.

La ventaja decisiva, para el comercio porteño y los consumidores del Rio de la Plata, estuvo en prescindir de la oferta peruana y capturar plata del interior y probablemente algún oro del Brasil, a través del comercio montevideano, que se asienta en las existencias de la Compañía.

De nuevo Letamendi nos ilumina sobre el momento vivido, al aconsejar a su socio cordobés sobre las expectativas de sus negocios:

"Si el proyecto del viaje a Chile no rueda sobre otra esperanza que la de la utilidad que dejase allí los Géneros llevados de aquí, debe ser despreciado, porque a más de estar aquella plaza abarrotada de Géneros, a unos precios que no corresponden a los de aquí, y a nuevas remesas que les van por estas vía, y les han traído de Lima, es el tiempo más crítico que se puede pensar, y el que se expone cualesquiera comprador a unas pérdidas irreparables, pues va expuesto a que se haga la paz repentinamente, y sin perspectiva de utilizar casi nada. (...), pero el tiempo es muy crítico y solo comprando Negros, y llevándolos a Lima, se podrá avanzar algo sin el eminente riesgo que advierto en el negocio de Ropas." Letamendi a Funes, 26 de septiembre de 1805. Martínez Paz (1918, pp. 157-158).

Puede notarse, siguiendo sus observaciones, que lo crítico del momento tenía que ver tanto con la competencia de los mercados como por la guerra contra los ingleses, quienes ya habían avanzado sobre el Cabo de Buena Esperanza obturando el tráfico asiático a Cádiz y amenazando en el Cabo de Hornos a los navíos que recurrieran a la ruta alterna. En su caso, a los pocos meses daría inició la toma de Montevideo e invasión al Rio de la Plata, que habría de trastornar la circulación en el complejo portuario.

En ese escenario, la oferta de géneros al mercado del Pacífico que los limeños los surtían con comodidad era poco rentable. Todo indica que la estrategia seguida por los comerciantes porteños estaba en su depósito y dejar que agotándose sus existencias los precios reaccionaran al alza. Pero también es notable que advierte sobre los tradicionales beneficios del comercio de esclavos con Lima, como una alternativa rentable que habría de cobrar relevancia con el comercio directo hacia África ${ }^{33}$.

33 Para la introducción de negros en el Rio de la Plata, con nuevas estimaciones y una interpretación holística véase Borucki (2011, pp. 81-107). Sobre el negocio de mercaderes porteños en el negocio de la trata directa Studer (1958) reseña los ciclos de negociación colonial. Para el ensayo de la Real Compañía de Filipinas véase Studer (1958, pp. 271-277) En particular 
Volviendo a la distribución en el territorio del virreinato y el espacio altoperuano, los beneficios de la distribución regional probablemente se dejaron sentir con los márgenes de ganancia que la Compañía ya advertía. Para ello, conviene recurrir a los testimonios que nos dejan las guías de despacho, en donde se registran los valores de factura y, en algunos casos, el "valor en plaza".

Así, mediante el registro de guías que lo consignan, podemos advertir un margen de incremento que en el caso de algunas cargas de las fragatas van del 60 al 150\%, dependiendo de los efectos y la distancia. El cuadro A10 nos permite entender que los despachos por la ruta del Interior a Potosí y Chuquisaca, pasando de Córdoba a Tucumán, Salta y Jujuy, generaron mayores beneficios. Merece también anotarse que el radio de Tucumán, Santiago del Estero y Catamarca como centros de producción textil absorvieron buena parte de la demanda de tejidos el primero y textiles el segundo. En su caso, Santa Fe y Asunción se decantan por textiles y estampados, o bien mahones angostos de algodón para Montevideo ${ }^{34}$ (Apéndice cuadro A10).

¿Cómo se pagaba este consumo y un diferencial de precios tan alto? La posibilidad de alcanzar altos precios de plaza, obtener a cambio plata a la vez que garantizar con ello el ciclo circulatorio cuando las exportaciones no alcanzan a compensar las importaciones, nos plantean un problema que ya Halperin (1972) había advertido:

"Solo la existencia de una comercialización excepcionalmente costosa podía asegurar un equilibrio, nivelado en los centros productores -de plata y oro- (y ante todo en el Alto Perú) lo que en Buenos Aires aparecía radicalmente desnivelado" (pp. 48-49)

Es la plata del Alto Perú, con sus efectos de arrastre en las economías del Interior, la savia que irrigaba el comercio de importación rioplatense, exactamente en el sentido contrario al que los efectos orientales encaminaron su circulación en los distintos mercados del virreinato y altoperuanos. De esta manera, la captura de la carga de ambas fragatas por el

para el caso de Tomás Antonio Romero, el actor privilegiado del régimen de licencias para la trata directa, véase Galmarini (2000, pp. 81-104).

34 "Salta y Jujuy eran dos ciudades claves en estos nudos mercantiles por su localización y capacidad de control. Eran las dos ciudades que controlaban la unión de dos rutas (la que venía desde Buenos Aires pasando por la cadena de ciudades y la que venía desde el pacífico y ensamblaba con la ruta del Despoblado) y también el paso de los productos que circulaban entre las distintas zonas ambientales" Assadourian y Palomeque (2014, p. 47). 
comercio porteño se corresponde a la función receptora de metales, distribuidora de importaciones y articuladora de mercados locales y regionales.

Pese a las dificultades de la invasión el comercio de efectos orientales siguió su curso, aunque en una escala más atenuada, con buenos negocios para los comerciantes porteños, tanto en tiempos de paz como de guerra. Formar parte de la red de distribución de la Real Compañía, particularmente de Letamendi, arrojó beneficios que más tarde habrían de decaer.

\section{ESPACIALIDAD Y REDES DE NEGOCIACIÓN: LA COMPAÑÍA Y SUS BENEFICIARIOS LOCALES}

Un examen de los despachos de mercancías de la Real Compañía desde Buenos Aires al Interior, Litoral y el espacio andino, nos permite mostrar la red que se configuró con la distribución de efectos asiáticos. Un esquema de circulación que incluía intermediarios en plazas como Montevideo, Mendoza, Córdoba y Salta, gracias al despliegue de capacidades de distribución y movilización de recursos que produjo la arribada para el sistema de transporte, combinando navegación pluvial, acarreo en carretas y recuas de mulas (Apéndice cuadro A11).

En el periodo de diecisiete meses, entre mayo de 1805 y octubre de 1806, se distribuyeron efectos por más de 56 mil pesos en una sucesión episódica de 67 despachos que cubrieron las principales plazas de las rutas arriba señaladas. A través de la figura de Letamendi, se pueden monitorear 31 corresponsales de la Real Compañía y una secuencia de distribución, actores y sus aglomeraciones: Córdoba, Salta/Jujuy en el Interior; Mendoza/Santiago y Potosí/Chuquisaca en el comercio transandino y el puerto de Montevideo hacia el Atlántico luso americano.

Por actores del comercio merecen destacarse, por importes de sus despachos en valores superiores a los mil pesos, a Dámaso Gómez y Lorenzo Recalde, en Córdoba; Francisco Araos y Francisco de Urteaga en Salta; Juan Nadal, Manuel de Entrambasaguas (sic) y Manuel Pinto en Jujuy, y Ángel Fernández en Corrientes. Considerando los polos distantes, además de Manuel de Ortega en Montevideo, Pedro Nicolás de Chopitea en Santiago de Chile y el norte minero Pablo Soria y Juan Pablo de los Santos en Potosí, así como Juan José de Urquiza en Chuquisaca. Este grupo, entre los mayores clientes de la Compañía, se verán igualmente articulados a esa red de distribución que conviene examinar en su escala local (Gráfico 1).

En la convergencia de plazas y actores se pueden advertir racimos de negocios en la espacialidad mencionada, en 16 localidades donde una amplia red de 41 comerciantes vinculados a Letamendi aparecen como 


\section{GRAFICO 1}

Relación de consignatarios, valores y lugares de despacho de mercancías de la Real Compañía de Filipinas, 1805-1806

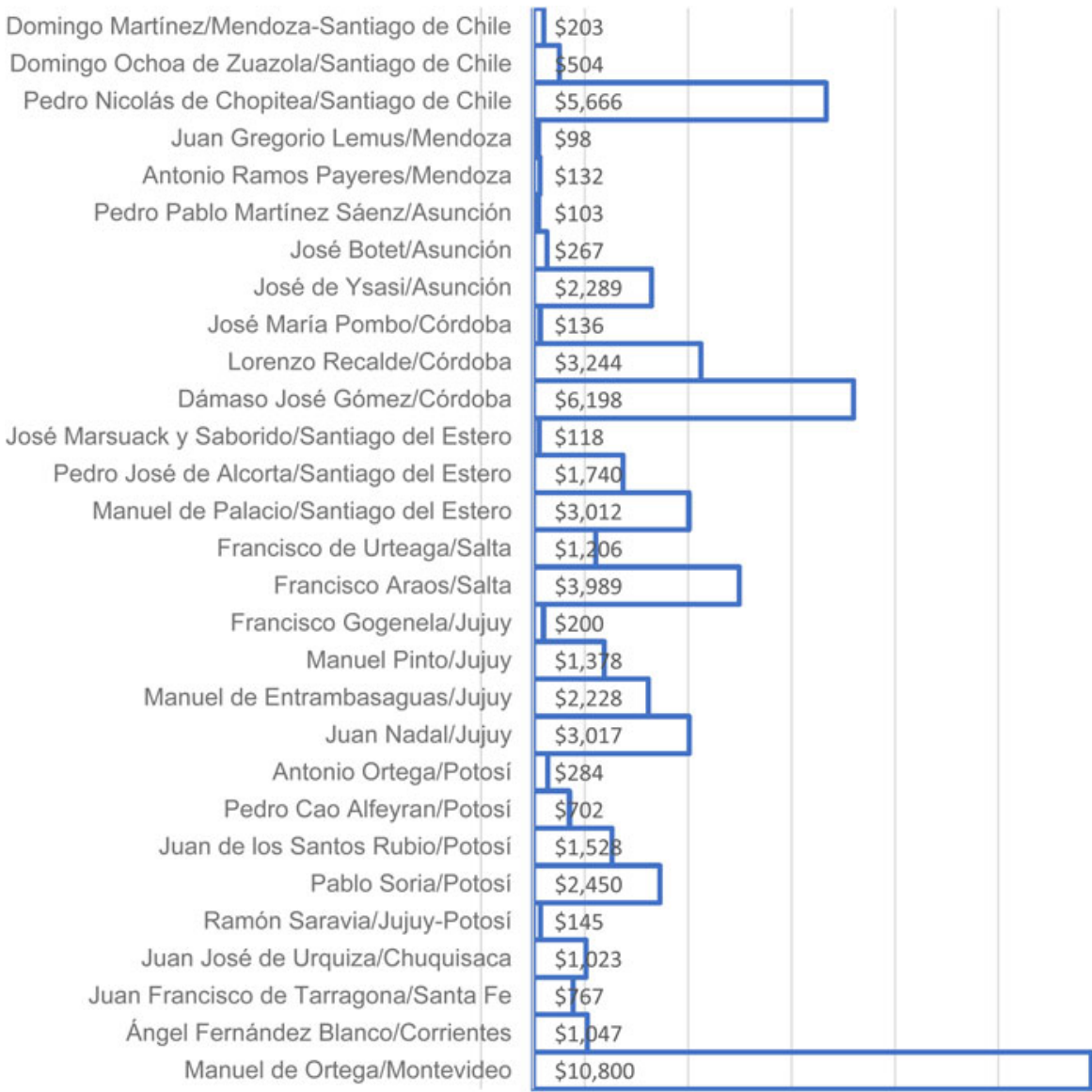

Fuente: véase el texto.

los introductores de efectos asiáticos. Pongamos el acento en advertir que las rutas están dibujadas en función de los ejes de distribución, que los nodos de lugar reflejan la mayor densidad de destinatarios, así también como el eje de vinculación del Interior con el espacio altoperuano y transandino nos estarían confirmando las observaciones de Assadourian y Palomeque, sobre la reconfiguración del espacio económico peruano en este momento, desde la margen rioplatense y las arterias de circulación de importaciones y plata (Gráfico 2). 


\section{GRAFICO 2}

Red de distribución de Mercancías Asiáticas. 1805-1806

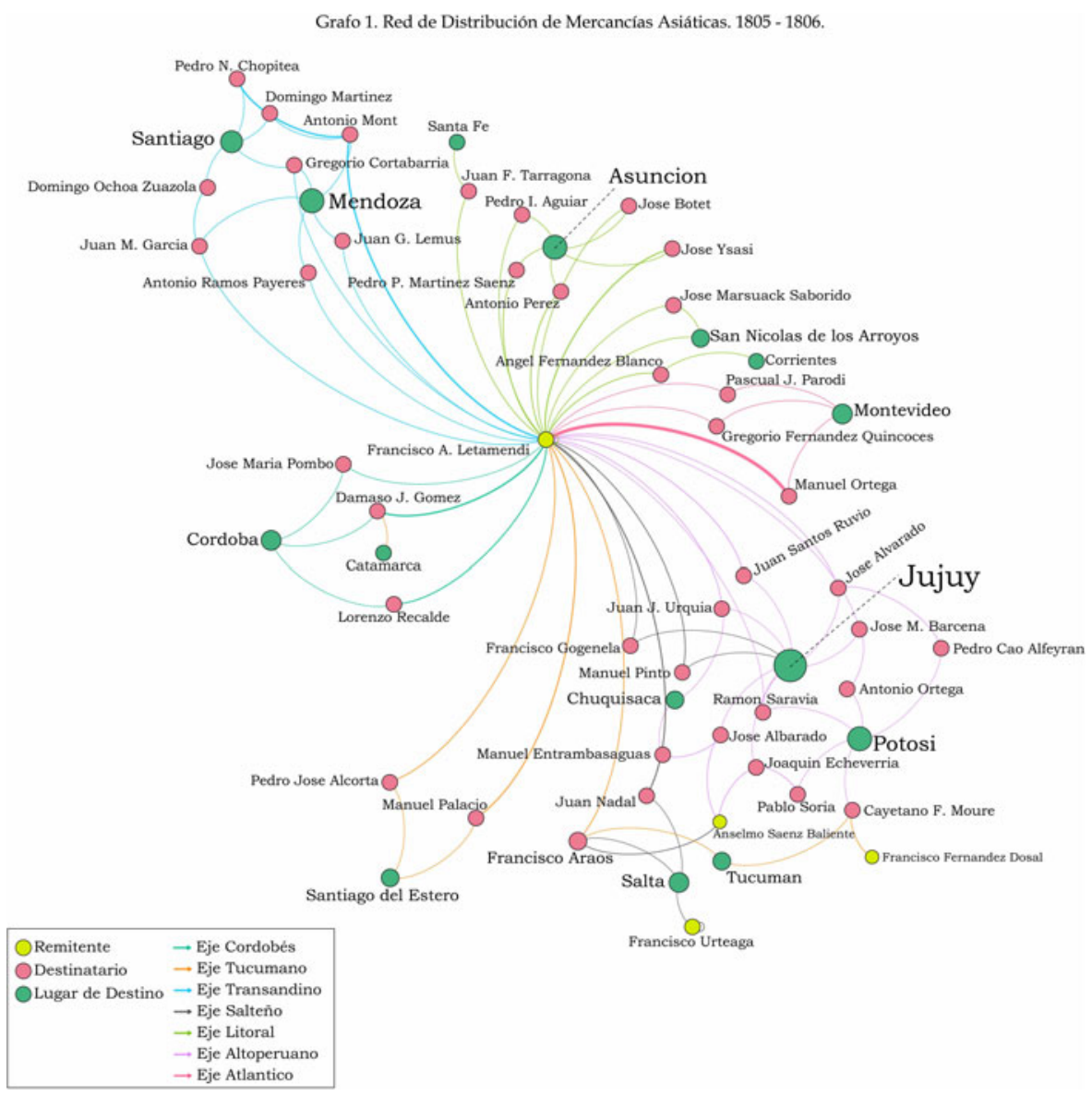

Fuentes: véase el texto.

\section{LOS COSTOS DE LA GUERRA: INTERESES LOCALES Y PÉRDIDAS IMPERIALES}

La guerra había precipitado una crisis financiera que la Compañía lastraba desde décadas, ya que según los directores de la Junta de Gobierno en el Balance al 31 de diciembre de 1804 estimaban las pérdidas en 
671.761 pesos 5 reales, entre el déficit que alcanzaba los 287.107 pesos 6 reales y los del fondo de seguros por 384.653 pesos 7 reales $^{35}$.

Consecuente a las malas nuevas, los directores de la Compañía plantearon al ministro Soler suspender la Junta General de accionistas de ese año, una vez enterados del desastre padecido en el Rio de la Plata, y por los efectos que puede tener en un contexto más amplio de quebrantos:

“...la publicidad de esta pérdida que hace subir a un punto considerable las habidas ya por efecto de la guerra, la notoriedad a que la Compañía esta amenazada de hallarse en otras exorbitantes, pudiera disminuir su crédito en términos que se viese sumamente embarazada para su giro y operaciones sucesivas, y aun para hacer uso de él en las atenciones de que esta encargada para el Real servicio. No pudiendo pues darse a los Accionistas en las fatales circunstancias del día el menor socorro o dividendo, porque éste únicamente debe hacerse de la ganancias, y el Balance solo presenta perdidas; no habiendo lugar a prometerles fundadamente en la Exposición de las operaciones, que podrá hacérseles repartimiento en alguna época próxima; privada en fin la Junta de Gobierno hasta de la esperanza de poderles presentar alguna idea consoladora, pues no se les puede dar noticia hasta su tiempo de las Expediciones emprendidas por pabellón neutral para no comprometer su éxito, entiende la misma con nosotros que lejos de ser útil a la Compañía sería perjudicial y aun funesta a su crédito y operaciones la celebración de la Junta General en el próximo diciembre al tenor de lo prevenido ..."36

Pese a que la Compañía había logrado obtener una utilidad por más de 400 mil pesos, según informó el Ministro Soler en la Junta General de 23 de diciembre de 1805, la plata no pudo remitirse a Cádiz durante los años siguientes por el estado de guerra y la sucesiva incomunicación marcada por la inseguridad y la ocupación francesa en España.

En la Junta de gobierno del 24 de enero de 1806, se pensó en la posibilidad de extraer 500 mil pesos "en oro y plata" producto de las expediciones que arribaron a Buenos Aires "enviándolos por tierra para preservarlos de los riesgos de mar y de enemigos, y que desde el Janeiro se conducen a Lisboa en buques y como propiedad portuguesa" ${ }^{37}$.

35 En sus palabras: "la cuenta dio un déficit de reales de vellón 5,742,155 en los capitales de su trafico que con los $7^{\prime} 693,077$ en el fondo de seguros, hacen una perdida en ambos ramos de reales de vellón 13`435,232".

36 Huizi, Lizaur y Gandásegui a Soler. Madrid, 15 de noviembre de 1806. AGI Filipinas, 991.

37 AGI Filipinas, 991. 
Las pérdidas fueron tanto en el beneficio esperado de los efectos desembarcados, ya que se admitió por los factores que tuvieron que expender la carga a los comerciantes locales para "salvarla" de la apropiación de los invasores, así como por la confiscación de platas y destrozos en los navíos.

Según el Informe a la Junta de gobierno de la Compañía, los quebrantos que sufrió la estancia en Buenos Aires fueron considerables, ya que por "conductos indirectos" se tuvo noticia de que "los ingleses habían arrancado" a Sarratea "cosa de 240 mil pesos en plata", confirmándose más tarde por medio de la Gaceta Extraordinaria de Londres del 13 de septiembre de 1804, del "funestísimo suceso" que relataba cómo se "habían cogido los enemigos al Comisionado de la Compañía 238 mil pesos". El propio Sarratea escribió, el 13 de julio de 1805, avisando que durante la ocupación "sacaron de su poder los enemigos hasta la suma de 251,742 pesos 5 reales corrientes de la pertenencia de la Compañía" ${ }^{38}$. La disparidad de cifras añade otro elemento de opacidad.

Las reclamaciones ante los Lores de la Tesorería y el Tribunal del Almirantazgo, con el argumento de que la carga era de particulares y no del Monarca beligerante, no tuvieron éxito y al final desistieron por "los tramites delicados y sumamente costosos que habrían de seguirse", y confían poco en que se recuperen los caudales al "hacerse la paz o después vuelvan los ingleses a recobrar los sentimientos de honor y de justicia que debieran gobernar siempre a los Pueblos civilizados"

Por otra parte, no fueron menores los daños a las embarcaciones, que ya acusaban la fatiga de la navegación: de la "Princesa de Asturias", inspeccionada a su arribo a Montevideo, se advirtió que en la banda de estribor de su bodega se encontraron trece maderos podridos, y en lado babor once. Entre el puente de la bodega seis podridos y en babor otros seis, en el "combo de estribor" uno y en babor otro. En la mirra de estribor, dijo el carpintero, "que el buque tenía muchos maderos podridos". El mismo reconoció que "recorriendo el Buque todas las goteras y regalas puede aguantar dos años y seguir su viaje a España y a otro puerto que le acomode dándole una recorrida de firme" ${ }^{39}$.

Después de las contingencias de la invasión, se tomó nota de la rapiña de que fueron objeto las fragatas "Santo Domingo" y "Princesa de Asturias" durante su cautiverio, estimando el costo en más de tres millones de reales de vellón, alrededor de 160 mil pesos, en "cascos, quillas y aparejos de que los ingleses se apoderaron en Montevideo".

Antes de volver a Cádiz, la "Princesa de Asturias" además de reponer algunos elementos de cubierta, debió "darle carena de firme en todas sus partes de calafatería, componga cuarteles, varios reparos, y lo que

38 AGI, Filipinas, 991.

39 AGNU-Ex Archivo y Museo Histórico General, Aduana de Montevideo, Caja 265, Año 1805 carpeta no. 48 . 
descubra el calafate" regulándose a un juicio prudente en 17 mil pesos el costo, "no incluyendo sus palos que tienen unas pudriciones por el centro que les penetran la mayor parte de su grueso: de esto no se puede tratar sin la precisa necesidad de sacarlos del Buque desembucharlos (sic) y desarmarlos a ver si admiten composición o ser de menester excluirlos por su mal estado" ${ }^{40} \mathrm{El}$ retorno sería su último viaje, antes de ser desguazada en la península.

Por su parte, la "Santo Domingo de la Calzada" terminó sus días frente al puerto de Montevideo al ser alcanzada por el fuego enemigo, tras haber sido convertida en depósito de armas y pólvora por los defensores leales a la Corona ${ }^{41}$.

Si bien el ministro Soler intento disminuir el impacto de las pérdidas por la invasión, años más tarde, en la "Representación hecha al Congreso Nacional por la Junta de Gobierno de la Real Compañía de Filipinas", impresa en Cádiz con fecha 5 de agosto de 1811, donde hacía un balance de deudas y pérdidas que recordaban los tropiezos del Rio de la Plata, calculando en "dinero y en efectos" un quebranto por de siete millones de reales de vellón, alrededor de 350 mil pesos ${ }^{42}$.

El episodio rioplatense resulta interesante porque da testimonio de los aspectos más frágiles de la Compañía: un déficit contable y financiero que presionaba su liquidez; una continua dependencia del favor real, que no le alcazaba en privilegios para aumentar su competitividad; una descarnada lucha contra busques enemigos, corsos y hasta piratas chinos que con información privilegiada asaltaban navíos, como ocurrió con la "Ferroleña" en las costas de Macao; una flota deteriorada y frecuentemente expuesta a los rigores de largas navegaciones y, finalmente, un modelo de gestión de privilegios destinado a fracasar al quedar atado a la suerte de la Corona en una época de guerras y revoluciones.

El desenlace del episodio, entre buenos negocios y desastres de la guerra, marcaron una época de incertidumbre con la cuota de violencia, estafa y rapiña que no fue ajena a la historia de la globalización comercial.

\section{A MODO DE CONCLUSIÓN: INTUICIONES Y CONJETURAS}

Las posibilidades de comprender la complejidad y el contradictorio mundo de conexiones que produjo la globalización comercial de fines del siglo XVIII, en este caso en la escala de una lucha de hegemonía por el control marítimo de la circulación de efectos orientales, merece múltiples aproximaciones. Aquí hemos hecho una observación que nace de un "estado

\footnotetext{
40 AGNU, Montevideo. Aduana, Libro Maestro de Capitanía de puerto, 265.

41 Diaz-Trechuelo 1965, p. 227.

42 BNE/R 61013.
} 
de guerra" entre imperios, pero que tiene su desenlace en una cadena de eventos inesperados y decisiones que reflejan tanto la dinámica de los mercados, como el papel de las expectativas y anticipación de los actores.

Recuperamos en este trabajo la reconstrucción de la accidentada navegación de la "Princesa de Asturias" y "Santo Domingo de la Calzada", la importancia de un microanálisis de la política imperial, las decisiones de la empresa monopolista y las expectativas de los actores locales. Notamos, de la misma manera, la importancia que los objetos le dieron al episodio: una explosión de mercado que produjo un extendido consumo de efectos "exóticos", su consecuente giro en la escala de los negocios y una oportunidad para los actores locales de posicionarse en el mercado macrorregional de efectos asiáticos.

El examen de la carga y sus mercancías, gracias a la excepcionalidad de la arribada y sus contratiempos, nos permitió conocer los precios de origen y el sistema de costes y costas de la negociación que nos remitieron a una tasa de beneficio entre la Compañía, los actores locales del tráfico y la dinámica de la circulación interior. El "comercio de pacotilla" nos dio testimonio sobre la estructura de oferta de efectos asiáticos y la enorme variedad de textiles, estampados, tejidos, sedas, joyas, especiería, curiosidades y objetos lúdicos que retratan los gustos de consumidores seducidos por la variedad y calidad de las mercaderías orientales.

La composición diversa de ambas fragatas, en función del origen de sus cargas, nos revela la enorme importancia de los textiles y estampados de la India que, por su diversidad y precio, muy probablemente fueron dirigidos lo mismo a las elites que a un consumidor de recursos modestos, a los talleres de ropa y costura, así como a localidades distantes que carecían de ellos con el consecuente impacto adverso en el consumo de los textiles de la tierra.

Como se pudo advertir a través del examen de las guías de despacho, en la víspera de la primera invasión inglesa, su circulación se desplegó sobre la cobertura regional y de larga distancia que posicionaban a Buenos Aires como el puerto clave del Atlántico sur. Son muy significativos los recorridos al Interior a través de Córdoba, Tucumán, Salta y sus áreas regionales de influencia, hasta alcanzar la villa del Potosí y Chuquisaca. Por otra parte, la dirección de la carga nos señala el articulado de la vinculación con Brasil, a través del puerto atlántico de Montevideo, y con Chile por el puerto seco transandino de Mendoza y el comercio cordillerano. No deja de ser interesante que la oferta de efectos orientales llegará hasta Asunción de Paraguay, siguiendo la ruta del Litoral desde San Nicolás de los Arroyos, Santa Fe y Corrientes. La descarga de efectos orientales produjo quizá un "choque de mercado" que nos reveló la articulación territorial y el peso de la demanda de cada ruta, cada plaza y en especial de sus actores involucrados. Una investigación ulterior aconseja seguir a los actores en sus redes locales de distribución, lo que aquí apenas esbozamos, 
así como también la dinámica de los precios en los distintos mercados locales con la información obtenida.

Para la Real Compañía de Filipinas el episodio puso al descubierto sus limitadas posibilidades de controlar el tráfico con beneficios contantes y sonantes: su estrategia de internación rioplatense fue tardía, su organización pesada, su crisis financiera pronunciada y su capacidad para negociar políticamente con otras potencias mediocre. Quizá su modelo de organización, dependiente del favor real y los privilegios, la acercaban más al monopolio que a una compañía de comercio con autonomía en sus decisiones: allí puede situarse la explicación de sus quebrantos que la crisis rioplatense vino solamente a acusar.

Por contraste, puede advertirse que, para los actores locales, incluso sus comisionados, el episodio les dejó beneficios que en otras circunstancias no eran alcanzables. La oferta excepcional que rebajó los precios de arribada y multiplicó los del comercio interior, la acumulación de existencias que les permitió administrar los mercados locales, los beneficios que generaron las reparaciones y calafateo dieron un empuje adicional a la economía de los puertos y, finalmente, los colocó en las corrientes de circulación global. Un saldo desigual, en un mundo desigual, que profundizo la desigualdad de la globalización arcaica y que precipitó el derrumbe del modelo monopólico de circulación de efectos orientales en América. Queda por indagar, en la escala local de lo global, los procesos menudos de un cambio planetario de las economías de mercado en donde la región iberoamericana jugó un papel determinante.

\section{AGRADECIMIENTOS}

Received 8 January 2019. Accepted 5 June 2019.

La investigación se inscribe en mi proyecto "'Redes sociales y negocios globales en el mundo iberoamericano, siglos XVII-XIX", CONACyT/México (CB-2011-01/168120). El pago Open Access de esta investigacion ha sido apoyado y financiado por el proyecto GECEM (Global Encounters between China and Europe: Trade Networks, Consumption and Cultural Exchanges in Macau and Marseille, 1680-1840), proyecto acogido por la Universidad Pablo de Olavide (UPO). El proyecto GECEM esta financiado por el ERC (European Research Council) Starting-Grant, ref. 679371, bajo el Programa de Investigacion e Innovacion Horizon 2020 de la Union Europea, www.gecem.eu. El Investigador Principal es el profesor Manuel Perez-Garcia (Profesor titular en la Shanghai Jiao Tong University e Investigador Distinguido en la UPO) Esta investigacion forma igualmente parte de las actividades académicas de la Global History Network in China (GHN) www.globalhistorynetwork.com, de la que formo parte como miembro del comite fundador. Manuel Perez-Garcia es el director y 
fundador de la GHN. En el Lateinamerika Institut de la Frei Universität de Berlín, gracias a la hospitalidad de S. Rinke y el apoyo de la UNAM, a través de DGAPA, tuvimos las condiciones para escribirlo. Las recomendaciones y críticas de S. Palomeque y F. Jumar fueron de gran utilidad. Mi gratitud a S. Serrano, por la gestión y sistematización de datos; a G. Fabián Alonso del AGN en Argentina y A. Sánchez del AGI, por su ayuda. Finalmente, agradezco los estimulantes comentarios de los revisores anónimos, que promovieron una mejor reflexión.

\section{MATERIALES SUPLEMENTARIOS}

Para el material complementario que acompaña a este artículo, ir a https://doi.org/10.1017/S0212610919000259.

\section{FUENTES Y PUBLICACIONES OFICIALES}

Archivo General de Indias (AGI), AGI Filipinas 991. "Carta de los directores de la Real Compañía de Filipinas Huizi, Lizaur y Gandásegui a Soler”, 14 de febrero de 1804.

Archivo General de Indias (AGI), Filipinas 991. "Carta de los directores de la Real Compañía de Filipinas Huizi, Lizaur y Gandásegui a Soler”, Madrid, $1^{\circ}$ de mayo de 1805.

Archivo General de Indias (AGI), Filipinas, 991. "Carta de D. Martin de Sarratea, factor en Buenos Aires, a los directores de la Real Compañía de Filipinas”. Madrid, 13 de julio de 1805.

Archivo General de Indias (AGI), AGI Filipinas 991. "Carta de los directores de la Real Compañía de Filipinas Huizi, Lizaur y Gandásegui a Soler”. Madrid, 10 de octubre de 1805.

Archivo General de Indias (AGI), AGI Filipinas 991. "Carta de los directores de la Real Compañía de Filipinas Huizi, Lizaur y Gandásegui a Soler". Madrid, 20 de marzo de 1806.

Archivo General de Indias (AGI), AGI Filipinas 991. "Carta de los directores de la Real Compañía de Filipinas Huizi, Lizaur y Gandásegui a Soler”. Madrid, 15 de noviembre de 1806.

Archivo General de Indias (AGI), AGI Filipinas 991. Informe a la Junta general de accionistas de la Real Compañía de Filipinas celebrada en 24 de julio de 1807. Madrid.

Archivo General de Indias (AGI), Ultramar 640. "Actas de Junta directiva de la Real Compañía de Filipinas, sesión del 10 de febrero de 1804". Madrid.

Archivo General de la Nación Argentina (AGNA), Sala IX, Colonia, 45-2-6. "Relación de los bultos, cajones y sacos de varios efectos del Asia, facturados en Manila el 5 de diciembre de 1804 y en Cantón el 15 de febrero de 1805, el valor por cuenta y riesgo de la Real Compañía de Filipinas". Buenos Aires.

Archivo General de la Nación Argentina (AGNA), Sala XIII, Contaduría colonial, 16-7-4. "Sobre el reconocimiento, confrontación y entrega a Don Martín Simón de Sarratea del cargamento que condujo la Fragata Española nombrada la Princesa, procedente de Calcuta de cuenta de la Real Compañía de Filipinas". Buenos Aires, 1805. 
Archivo General de la Nación Argentina (AGNA), Sala XIII, Contaduría colonial, 16-7-4. "Testimonio de Joaquín Proyet, administrador de la Aduana Buenos Aires, 1 mayo 1805”. Buenos Aires.

Archivo General de la Nación Argentina (AGNA), Sala XIII, Contaduría colonial, 16-7-4. "Factura general de los efectos de Asia que en calidad de pacotillas hemos permitido embarcar en la fragata Princesa, de la Real Compañía de Filipinas con arreglo a la concesión que fue comunicada por la Dirección de la misma en carta de 16 de marzo ultimo, y a las facturas particulares que nos han presentado los respectivos interesados". Celedonio Laterita, factor de la Real Compañía de Filipinas. Calcuta, 4 de diciembre de 1804.

Archivo General de la Nación Argentina (AGNA), Sala XIII, Contaduría colonial, 4-1-11, Libro de guías de la Aduana de Buenos Aires (2256), foja 358. 1 de febrero de 1806.

Archivo General de la Nación Argentina (AGNA), Sala XIII, Contaduría colonial. Libros de guías de la Aduana de Buenos Aires 934, 40-9-10, mayo-junio 1805; 936, 40-10-1, julio-agosto 1805; 937, 40-10-2, septiembre 1805; 939, 40-10-4 noviembre-diciembre 1805; 957, 41-1-11, febrero 1806; 958, 41-1-12, marzo-abril 1806; 959, 41-2-1, mayo 1806; 960, 41-2-2, junio-septiembre 1806; 961, 41-2-3, octubre-noviembre 1806.

Archivo General de la Nación Argentina (AGNA), Sala XIII, Contaduría colonial, 16-7-4. "Permiso concedido, con arreglo a la Real Concesión que nos fue comunicada por la Dirección en la misma carta de 16 de marzo de 1805".

Archivo General de la Nación Argentina (AGNA), Sala XIII, Contaduría colonial, 14-7-1. "Libro mayor de la Real Aduana de Montevideo del cargo de los ministros D Jose Prego de Oliver, administrador, D Luis de Herrerea, contador, para la cuenta del año de 1805". Montevideo.

Archivo General de la Nación de Uruguay (AGNU), Ex Archivo General Administrativo, Capitanía Puerto, Libro 95, "Libro Maestro de Entradas de Buques 1805- 1818". ff. $24 \mathrm{v}-25$

Archivo General de la Nación de Uruguay (AGNU), Ex Archivo y Museo Histórico, Aduana de Montevideo, Caja 265, Año 1805 carpeta no. 48.

Archivo General de la Nación de Uruguay (AGNU), "Reconocimiento de don Fernando Sánchez, Juan de Dios Álvarez y Francisco Ramírez, 20 de septiembre de 1805". Montevideo. Aduana, Libro Maestro de Capitanía de puerto, 265.

Biblioteca Nacional de España (BNE), Reservado, 61013. Representación hecha al Congreso Nacional por la Junta de Gobierno de la Real Compañía de Filipinas. Cádiz. imprenta Tormentaria, 1811.

\section{BIBLIOGRAFIA}

Assadourian, C.S. y Palomeque, S. (2014): "Los circuitos mercantiles del «interior argentino" y sus transformaciones durante la guerra de la independencia (1810-1825)". Cuadernos de Historia. Serie economía y sociedad. Núm. 13/14, pp. 37-58.

Assadourian, C.S. y Palomeque, S. (2001): "Importaciones de productos de castilla/europeos en Córdoba, 1800-1819" ". Andes, no. 12. Salta, Argentina: Universidad Nacional de Salta.

Bonialian, M. (2014): China en la América colonial. Bienes, mercados, comercio y cultura del consumo desde México hasta Buenos Aires. México: CONACyT/Instituto Mora.

Bonialian, M. y Hausberger, B. (2018): "Consideraciones sobre el comercio y el papel de la plata hispanoamericana en la temprana globalización, siglos XVI-XIX". Historia Mexicana, Vol. 68, Núm. 1 (269), julio-septiembre, pp. 197-244. 
Borucki, A. (2011): “The Slave Trade to the Rio de la Plata, 1777-1812: Trans-Imperial Networks and Atlantic Warfare”. Colonial Latin American Review, Vol. 20 (1), April, pp. 81-107.

Carmagnani, M. (2012): Las islas del lujo. Productos exóticos, nuevos consumos y cultura económica, 1650-1800. Madrid: Marcial Pons/El Colegio de México.

CARmagnani, M. (2004): El otro Occidente. América Latina desde la invasión europea hasta la globalización. México: FCE/El Colegio de México.

Delgado Ribas, J. M. (2007): Dinámicas imperiales (1650-1796). España, América y Europa en el cambio institucional del sistema colonial español. Barcelona: Bellatera ediciones.

Diaz-Trechuelo, M. L. (1965): La Real Compañía de Filipinas. Sevilla: Escuela de Estudios Hispano-Americanos.

FlynN, D. O. y GIRÁLDEZ, A. (2014): "Los orígenes de la globalización en el siglo XVI”, en Hausberger, B. e Ibarra, A., Oto y plata en los inicios de la economía global: de las minas a la moneda, México: El Colegio de México, pp. 29-76

FlynN, D. O. and GiRÁldez, A (2008): “Born Again: Globalization's Sixteenth Century Origins (Asia versus European Dynamics)”. Pacific Economic Review, 13: 3, pp. 359-387.

GaLmarini, H. R. (2000): Los negocios del poder. Reforma y crisis del Estado, 1776-1826. Buenos Aires: Ediciones del Corregidor.

Generelo Lanaspa, J. J. (1998): “El Fondo Latre y Aísa (1767-1828)”. Zaragoza: Actas del VII Congreso Internacional de Historia de América, pp. 337-347.

Halperin Dongui, T. (1972): Revolución y guerra. Formación de una élite dirigente en la Argentina criolla. Buenos Aires: Siglo XXI editores.

Hausberger, B. (2018): La globalización temprana. México: El Colegio de México.

Hausberger, B. e Ibarra, A. (2014): Oro y plata en los inicios de la economía global: de las minas a la moneda, México: El Colegio de México.

IbARRA, A.AlCANTARA, A. y JumAR, F. COORDS. (2018): Actores sociales, redes de negocios y corporaciones en Hispanoamérica, siglos XVII-XIX. México: UNAM/CONACyT/Bonilla Artigas.

JumAR, F. (2006): "El comercio ultramarino por el complejo portuario rioplatense y la economía regional, 1714-1778”. Magallánica. Revista de Historia Moderna, Vol. 3 Núm. 5. https://fh.mdp.edu.ar/revistas/index.php/magallanica/article/view/2006

LiDA, M. (2004): "Las devociones religiosas y la familia Funes. Identidad familiar, escatología y política en Córdoba (1767-1810)", Cuadernos de Historia. Serie Economía y Sociedad. Núm. 6, pp. 191-213. Universidad Nacional de Córdoba.

Maestro Castañeda, J. C. (1998): "Rasgos biográficos del capitán de navío D Juan de Latre y Aísa". Zaragoza: Actas del VII Congreso Internacional de Historia de América, pp. 433-441.

Mariluz UrquiJo, J.M. (1984) "La China, utopía rioplatense del siglo XVIII". Revista de Historia de América, 98 pp. 7-31.

Martinez Paz, E. (1918): Papeles de Don Ambrosio Funes. Córdoba: Universidad Nacional de Córdoba/Bautista Cubas, editor.

Martinez Shaw, C. (2007): El sistema comercial español del Pacífico (1765-1820). Madrid: Real Academia de la Historia.

Moutoukias, Z. (2018): "Instituciones, comercio y globalización arcaica: una reflexión sobre las redes sociales como objeto y como herramienta a partir del caso rioplatense (siglo XVIII)". En Ibarra, A. Alcantara, A. y Jumar, F. (coords.) Actores sociales, redes de negocios y corporaciones en Hispanoamérica, siglos XVII-XIX. México: UNAM/CONACyT/Bonilla Artigas, pp. 141-182. 
Moutoukias, Z. (1988): Contrabando y control comercial en el siglo XVIII. Buenos Aires, el Atlántico y el espacio peruano. Buenos Aires: Centro editor de América Latina.

Muñoz SERrulla, M. T. (2015): La moneda castellana en los reinos de Indias durante la Edad Moderna. Madrid: UNED.

PéRez Garcia, M: (2017): "Historia global vs. eurocentrismo: revisión historiográfica, análisis de consumo y un caso de estudio comparativo entre China y Europa (1730-1808)". Investigaciones de Historia Económica, 13 (1), pp. 1-68.

STUder, E. F.S. DE (1958): La trata de negros en el Rio de la Plata durante el siglo XVIII. Buenos Aires: Universidad de Buenos Aires. 